\title{
Prevalence of bruxism and emotional stress and the association between them in Brazilian police officers
}

\section{Andréa Lúcia de Almeida Carvalho(a) \\ Altair Antoninha Del Bel Cury(b) Renata Cunha Matheus Rodrigues Garcia $^{(\mathbf{b})}$}

(a) Graduate Student; (b) PhD, Professor - Department of Prosthodontics and Periodontology, Piracicaba Dental School, State University of Campinas (UNICAMP), Piracicaba, SP, Brazil.

\begin{abstract}
This study aimed to assess the prevalence of bruxism and emotional stress in Brazilian police officers, due to exposure to stressful situations, and to assess the relationship between the type of work done by a police officer and the presence of bruxism and emotional stress. A cross-sectional study was conducted at the Military Police of the State of São Paulo, Campinas, SP, Brazil. The final sample included 394 male police officers (mean age $=35.5$ years). Bruxism was diagnosed by the presence of aligned dental wear facets associated with the presence of one of the following signs or symptoms: self-report of tooth-grinding, painful sensitivity of the masseter and temporal muscles, discomfort in the jaw musculature upon waking. The Stress Symptoms Inventory (SSI) was applied to evaluate emotional stress. The type of work done by the police was classified as organizational or operational, the latter being assumed as the more stressful since it exposes the police officer to life risk. The results showed a prevalence of bruxism of $50.2 \%$ and a prevalence of emotional stress of $45.7 \%$. The Chi-square test indicated an association between stress and bruxism $(P<.05)$. No significant association was found between emotional stress and type of work $(P=.382)$ or between bruxism and work activity $(P=.611)$. It could be concluded that emotional stress was associated with bruxism, independently of the type of work done by police officers.
\end{abstract}

Descriptors: Bruxism; Stress, psychological; Police.

\section{Corresponding author:}

Renata Cunha Matheus Rodrigues Garcia

Departamento de Prótese e Periodontia

Faculdade de Odontologia de Piracicaba,

Universidade de Campinas (UNICAMP)

Av. Limeira, 901

Piracicaba - SP - Brazil

CEP: 13414-903

E-mail: regarcia@fop.unicamp.br 


\section{Introduction}

The etiology of bruxism is controversial and it has still not been possible to establish a direct cause and effect relationship for setting off this parafunctional activity. ${ }^{1}$ Three main etiological factors are involved in bruxism: morphological, patho-physiological and psychological factors. ${ }^{2}$ Morphological factors are related to occlusion and articular disharmony; patho-physiological factors include smoking, alcohol and drugs.

The psychological factor is related to depression, anxiety and emotional stress, which play an important role in starting and perpetuating bruxism, as well as in its frequency, and severity. ${ }^{3-5}$ Manfredini et al. ${ }^{6}$ (2004) found an association with anxiety, and with depressive and manic symptoms in bruxers. It is also believed that depressed, anxious and emotionally stressed individuals present a greater predisposition for developing bruxism, mainly during sleep, as a response to releasing daily emotional stress. ${ }^{7}$ Conversely, other studies suggest that there is no relationship between sleep bruxism and stress, as reported by Watanabe et al. ${ }^{8}$ (2003) and Pierce et al. ${ }^{9}$ (1995).

The role of work-related stress in physical health in police officers has long been a matter of concern. Police officers have been reported to have higher rates of cardiovascular and gastrointestinal disorders, divorce rates twice the national average, and suicide rates three times the national average. ${ }^{10-12}$ They are exposed to many different types of stress that may affect sleep quality and physical health, such as physical injury, injuring others in the line of duty, and witnessing death or injuries to other officers and civilians. The impact of this high rate of exposure on emotional health has long been a significant public health concern. ${ }^{13}$

In addition, police officers are exposed to chronic non-traumatic stress arising from the demands of their work environment. Therefore, it can be hypothesized that police officers engaged in operational activities, which include exposure to danger and risk of life, would be more stressed and would present more general bruxism than police officers who work in organizational or bureaucratic activities, who are supposedly exposed to a lower stress level.

This study aimed (1) to investigate the prevalence of bruxism and emotional stress and the association between them in male police officers; (2) to assess the association between the type of work done by police officers and bruxism and emotional stress.

\section{Material and Methods}

A cross-sectional study was conducted. A total of 700 police officers from the Military Police of the State of São Paulo, in the city of Campinas, SP, Brazil, were examined, and according to the inclusion criteria, only 394 were selected (mean age $=35.5$ ). They signed a consent form, approved by the local ethical committee.

The selection criteria was: to be dentate with a minimum presence of 26 teeth, including third molars, not to have made use of interocclusal appliances in the last 12 months and present good general health. The exclusion criteria included police officers presenting 1) temporomandibular joint dysfunction (TMJ) or orofacial problems, 2) absence of posterior dental support, 3) severe periodontitis, 4) deciduous teeth, complete or partial removable prostheses, 5) irreversible treatment for TMJ, 6) history of alcohol, drug or medication abuse, with possible effects on sleep or motor behavior, and 7) psychiatric or neurological disturbances as indicated by the medical charts of each police officer. After selection, the volunteers were submitted to a psychological assessment and clinical examination.

\section{Psychological assessment}

The actual presence or absence of stress was identified using a validated questionnaire, the Stress Symptoms Inventory (SSI). ${ }^{14}$

The SSI is composed by three question sessions. The first session is related to the alert stage of stress and it consists of 12 questions related to physical and 3 questions related to psychological stress symptoms that the volunteer has experienced in the last 24 hours of life. The second session, which concerns the resistance stage of stress, is composed of 10 questions about physical and 5 questions about psychological symptoms, experienced by the volunteer in the last week. The final SSI session deals with the exhaustion stage of stress and it consists of 12 questions about physical and 11 questions about 
psychological symptoms, experienced by the volunteer in the last month.

The police officers had to participate in all three of the SSI sessions and answer all the questions. The score was calculated by adding one point for each positive answer from each session. Police officers that presented scores above 6 for the alert stage, or up to 3 for resistance, or up to 8 for the exhaustion stage were considered to be stressed. ${ }^{14}$

\section{Anamnesis and clinical examination}

Subjects filled out a clinical card composed of data on identification and type of work currently carried out at the general headquarters, whether it was organizational or operational work. Organizational work was considered to be that of a bureaucratic nature carried out inside the headquarters; and operational duties as being those activities carried out outside the headquarters, such as highway and forestry policing and patrolling roads and prisons. These activities expose police officers to personal aggressions that would supposedly be more stressing than bureaucratic work, since they could place the police officers' very lives at risk.

The presence of discomfort in the masticatory muscles upon waking, and any self-report of tooth grinding in the last four weeks were also registered.

The clinical exam was carried out by a single researcher, who did not have access to the police officers' replies during the psychological assessments and clinical cards. Bruxism was diagnosed by the presence of aligned worn facets on the anterior and/or posterior teeth during protrusion and lateral movements of the mandible. Wear facets should present score 1, 2 or 3 in accordance with the ordinal scale of wear severity. ${ }^{15}$ Besides, to be considered as bruxist, subjects should present at least one of the following criteria: grinding bruxism sounds during sleep and/or while awake for a recent four week period, as noted by his bed partner or roommate; painful sensitivity upon touching the masticatory masseter and/or temporal muscles, discomfort in the jaw musculature upon waking. ${ }^{1}$

\section{Statistical analysis}

The data on bruxism and stress as well as a com- parison made of the prevalence of stress in subjects with and without bruxism were analyzed using the Chi-square test with a significance level of $5 \%$.

\section{Results}

The prevalence of bruxism in the 394 selected police officers was $50.25 \%(\mathrm{n}=198)$, of whom only $64.6 \%$ were aware of the presence of this parafunction. The presence of emotional stress was recorded in $45.69 \%(n=180)$ of them, and among the stressed police officers almost half $(48.3 \%)$ reported grinding their teeth while asleep and/or awake.

Significant association $(P=.0004)$ was found between the presence of emotional stress and bruxism among police officers (Table 1 ).

No significant difference $(P=.382)$ was found for the association between stress and type of work (Table 2). There was also no significant difference $(P=.611)$ in the association between bruxism and type of work (Table 3).

\section{Discussion}

This study attempted to assess the relationship between general bruxism behavior and emotional stress by evaluating a specific population composed

Table 1 - Presence of bruxism and emotional stress and the association between them among police officers $(n=394)$.

\begin{tabular}{l|c|c|c}
\hline \multirow{2}{*}{ Bruxism } & Absence of Stress & Presence of Stress & \multirow{2}{*}{ Association } \\
\cline { 2 - 3 } & $\mathrm{n}$ & $\mathrm{n}$ & \\
\hline Absence & 124 & 72 & \\
\hline Presence & $90^{*}$ & $108^{*}$ & P .0004 \\
\hline Total & 214 & 180 & \\
\hline
\end{tabular}

Chi-square $=12.592 ; *$ P-Value $=.0004$.

Table 2 - Association between emotional stress and police officers' type of work.

\begin{tabular}{l|c|c|c}
\hline \multirow{2}{*}{ Stress } & \multicolumn{2}{|c|}{ Type of Work } & \multirow{2}{*}{ Total } \\
\cline { 2 - 3 } & Organizational & Operational & \\
\cline { 2 - 3 } & $\mathrm{n}$ & $\mathrm{n}$ & \\
\hline Absence & 58 & 156 & 214 \\
\hline Presence & 56 & 124 & 180 \\
\hline Total & 114 & 280 & 394 \\
\hline
\end{tabular}

Chi-square $=.764 ; \mathrm{P}$-Value $=.382$. 
Table 3 - Association between bruxism and police officers' type of work.

\begin{tabular}{l|c|c|c}
\hline \multirow{2}{*}{ Bruxism } & \multicolumn{2}{|c|}{ Type of Work } & \multirow{2}{*}{} \\
\cline { 2 - 3 } & Organizational & Operational & \multirow{2}{*}{ Total } \\
\cline { 2 - 3 } & $\mathrm{n}$ & $\mathrm{n}$ & \\
\hline Absence & 59 & 137 & 196 \\
\hline Presence & 55 & 143 & 198 \\
\hline Total & 114 & 280 & 394 \\
\hline
\end{tabular}

Chi-square $=.259 ;$ P-Value $=.611$.

of police officers who perform organizational or operational duties.

Some authors emphasize the importance of discriminating between sleep-related bruxism and bruxism during wakefulness, because both types may have a different etiology $y^{4,16,17}$ and may influence correlation studies. ${ }^{16}$ According to Manfredini et al. ${ }^{18,19}$ (2005), sleep- and awake-bruxism seem to have different pathogeneses and they are hard to be clinically discriminated. Polysomnography represents the standard of reference for the diagnosis of sleep bruxism, but its use is limited by its high cost. ${ }^{18,19}$ The present study considered bruxism in general, because the population studied could be considered to be more stressed than the public in general, and most of the related articles ${ }^{18,19}$ do not distinguish adequately between the two phenomena.

The prevalence of bruxism $(50.2 \%)$ in this study was found to be lower than that found by Wigdorowicz-Makowerowa et al. ${ }^{20}$ (1979), who observed a prevalence of $58.7 \%$ in 20 to 45 year-old soldiers. However, their bruxism frequency calculation took into consideration the bruxism associated with TMJ. This study excluded police officers presenting TMJ, which may explain the results found.

Irrespective of their work, the prevalence of stress among the police officers was $45.7 \%$ ( $\mathrm{Ta}-$ ble 1), which is in agreement with the results of Collins, Gibbs ${ }^{21}$ (2003) who found $41 \%$ of police officers with stress-related mental ill-health. However, these data differ from those obtained by Bültmann et al. ${ }^{22}$ (2002) who studied a working population and found psychological distress in $25.42 \%$ of the sample. Thus, it would appear that when comparing the two, the proportion of police officers presenting stress is the double of that of the general population, supporting the idea that their occupation is generally perceived as being highly stressful. ${ }^{13}$

The prevalence association between emotional stress in police officers and bruxism was statistically significant $(P=.0004)$. It was also found that $36.7 \%$ of non-bruxist police officers $(n=196)$ presented emotional stress, while in the bruxist group (198) the percentage rose to $54.5 \%$. Although the frequency of emotional stress in police officers with bruxism was higher than that in those without bruxism, these results did not indicate a cause and effect relationship between emotional stress and bruxism (Table 1).

A similar result was observed by Pingitore et al. ${ }^{7}$ (1991), who found stress to be significantly related to general bruxism. In contrast, Pierce et al. ${ }^{9}$ (1995) found no overall relationship between electromyographic measures of sleep bruxism and self-reported stress. Watanabe et al. ${ }^{8}$ (2003) demonstrated that sleep bruxism behaviors are not highly influenced by day-to-day stress. However, the selected subjects for their studies included civilians, which could be considered as being a less stressful population when compared to the police officers.

The association between bruxism and emotional stress is still present irrespective of the type of work carried out by the police officer. This was to be expected since the studied population is considered to be more stressful than the general working population. ${ }^{21,22}$

Although there was greater prevalence of emotional stress observed in police officers with bruxism, some of them perform organizational duties, such as managerial structure, which one would assume to be less stressful. Thus, according to the hypothesis, police officers carrying out operational duties, being more exposed to confrontation, violence and day-today involvement in a variety of traumatic incidents, would present a greater prevalence of emotional stress - and consequently bruxism - than those who do organizational work, who are less subject to risks.

However, no significant association $(P>.05)$ was found between emotional stress and the police officers' work, or between bruxism and the police officers' work (Tables 2 and 3). A possible explanation 
refers to the sources of emotional stress in the police officers, which are related to two large groups: nature of the work and nature of the police organization. ${ }^{23}$ Thus, one should consider that although the police officer who carries out organizational work is not so exposed to personal risks, he is constantly facing up to internal pressures such as the headquarters hierarchy and rigid discipline, which may set off the occurrence of emotional stress. In this sense, according to some authors ${ }^{21,24-27}$, it is not operational aspects, such as risk of violence or exposure to traumatic events, which are perceived as most stressful,

\section{References}

1. Lavigne GJ, Rompré PH, Montplaisir JY. Sleep bruxism: validity of clinical research diagnostic criteria in a controlled polysomnographic study. J Dent Res. 1996;75(1):546-52.

2. Lobbezoo F, Naeije M. Bruxism is mainly regulated centrally, not peripherally. J Oral Rehabil. 2001;28(12):1085-91.

3. Arnold A. Bruxism and the occlusion. Dent Clin North Am. 1981;25:395-407.

4. Rugh JD, Harlan J. Nocturnal bruxism and temporomandibular disorders. Adv Neurol. 1988;49:329-41.

5. Tsai CM, Chou SL, Gale EN, McCall Jr WD. Human masticatory muscle activity and jaw position under experimental stress. J Oral Rehabil. 2002;29(1):44-51.

6. Manfredini D, Landi N, Romagnoli M, Bosco M. Psychic and occlusal factors in bruxers. Aust Dent J. 2004;49(2):84-9.

7. Pingitore G, Chrobak V, Petrie J. The social and psychologic factors of bruxism. J Prosthet Dent. 1991;65(3):443-6.

8. Watanabe T, Ichikawa K, Clark GT. Bruxism levels and daily behaviors: 3 weeks of measurement and correlation. J Orofac Pain. 2003;17(1):65-73.

9. Pierce CJ, Chrisman K, Bennett ME, Close JM. Stress, anticipatory stress, and psychologic measures related to sleep bruxism. J Orofac Pain. 1995;9(1):51-6.

10. Axelbend M, Vaile J. South Florida's approach to police stress management. Police Stress. 1979;1:13-4.

11. Blackmore J. Are police allowed to have problems of their own? Police Mag. 1978;1:47-55.

12. Violanti JM. Police suicide: epidemic in blue. Springfield: Charles C Thomas; 1996.

13. Neylan TC, Metzler TJ, Best SR, Weiss DS, Fagan JA, Libermam A et al. Critical incident exposure and sleep quality in police officers. Psychosom Med. 2002;64(2):345-52.

14. Lipp MEN, Guevara AJH. Empiric validation of stress symptoms inventory (SSI). Estud Psicol. 1994;11:43-9.

15. Pigno MA, Hatch JP, Rodrigues Garcia RC, Sakai S, Rugh JD. Severity, distribution, and correlates of occlusal tooth wear but rather, organizational aspects such as the managerial structure and work atmosphere.

Furthermore, while studying the police population in different countries, these authors came up with similar findings, which could lead one to suppose that the issue most associated with police stress is the same.

\section{Conclusions}

Within the limitations of this study, emotional stress was associated with bruxism, independently of the type of work done by the police officer.

in a sample of Mexican-American and European-American adults. Int J Prosthodont. 2001;14(1):65-70.

16. Glaros AG. Incidence of diurnal and nocturnal bruxism. J Prosthet Dent. 1981;45(5):545-9.

17. Ramfjord SP. Bruxism, a clinical and electromyographic study. J Am Dent Assoc. 1961;62:21-44.

18. Manfredini D, Ciapparelli A, Dell'Osso L, Bosco M. Mood disorders in subjects with bruxing behavior. J Dent. 2005;33(6):485-90.

19. Manfredini D, Landi N, Fantoni F, Segù M, Bosco M. Anxiety symptoms in clinically diagnosed bruxers. J Oral Rehabil. 2005;32(8):584-8.

20. Wigdorowicz-Makowerowa N. Epidemiological studies on prevalence and etiology of functional disturbances of the masticatory system. J Prosthet Dent. 1979;41(1):76-82.

21. Collins PA, Gibbs ACC. Stress in police officers: a study of the origins, prevalence and severity of stress-related symptoms within a county police force. Occup Med. 2003;53(4):25664.

22. Bültmann U, Kant I, Kasl SV, Beurskens AJ, van der Brandt PA. Fatigue and psychological distress in the working population: psychometrics, prevalence, and correlates. J Psychosom Res. 2002;52(6):445-52.

23. Spielberg CC, Westberry LG, Grier KS, Greenfield G. The police stress survey: sources of stress in law enforcement. Tampa (FL): Human Resources Institute; 1981.

24. Kirkcaldy B, Cooper CL, Ruffalo P. Work stress and health in a sample of U.S. police. Psychol Rep. 1995;76(2):700-2.

25. Kroes WH, Gould S. Job stress in policemen: an empirical study. Police Stress. 1979;1:9-10.

26. Violanti JM, Aron F. Ranking police stressors. Psychol Rep. 1994;75(2):824-6.

27. Violanti JM, Aron F. Sources of police stressors, job attitudes and psychological distress. Psychol Rep. 1993;72(3 Pt 1):899904. 